\title{
Research on Performance of Variable-Lead Rotor Twin Screw Compressor
}

\author{
Huagen $W u^{*}$, Jiankang Liu (D), Yuqi Shen $\mathbb{D}^{D}$, Mengtao Liang and Beiyu Zhang \\ Institute of Compressors, School of Energy and Power Engineering, Xi'an Jiaotong University, Xi'an 710049, \\ China; liujian9@stu.xjtu.edu.cn (J.L.); shenyuqi2016@stu.xjtu.edu.cn (Y.S.); lmtoto@stu.xjtu.edu.cn (M.L.); \\ zby555544444@stu.xjtu.edu.cn (B.Z.) \\ * Correspondence: hgwu@mail.xjtu.edu.cn
}

check for updates

Citation: Wu, H.; Liu, J.; Shen, Y.; Liang, M.; Zhang, B. Research on Performance of Variable-Lead Rotor Twin Screw Compressor. Energies 2021, 14, 6970. https://doi.org/ $10.3390 /$ en14216970

Academic Editor:

Alessandro Bianchini

Received: 23 September 2021

Accepted: 18 October 2021

Published: 24 October 2021

Publisher's Note: MDPI stays neutral with regard to jurisdictional claims in published maps and institutional affiliations.

Copyright: (c) 2021 by the authors. Licensee MDPI, Basel, Switzerland. This article is an open access article distributed under the terms and conditions of the Creative Commons Attribution (CC BY) license (https:/ / creativecommons.org/licenses/by/ $4.0 /)$.
Abstract: Twin-screw compressors are widely used in aerodynamics, refrigeration and other fields. The screw rotors are the core component of the screw compressor and affect the performance of the compressor. This paper focuses on variable-lead rotors. A thermal process simulation model considering leakage is established to calculate the efficiency of the compressor. Different lead change methods are compared by evaluating the contact line, exhaust port and simulation results. The results show that the compressor obtains better performance when the lead decreases rapidly on the discharge side. Furthermore, the effects of the wrap angle and internal volume ratio on variable-lead rotors are studied. The work provides a reference for the design of the screw compressor rotor.

Keywords: screw compressor; rotors; variable lead; design engineering

\section{Introduction}

The twin screw compressor is a rotary positive displacement machine used to compress gases to higher pressure. It has two parallel helical rotors, usually called the male and female, which mesh with each other. The compression chambers are enclosed by the helical surfaces of the meshing rotors and the inside surface of the case. During the rotation of the rotors, the volume of the working cavity periodically increases from zero to its maximum value and then decreases to zero, thus making suction, compression and discharge processes possible and achieving the goal of increasing the gas pressure. Twin screw compressors are deployed in many industries that require high performance, low noise and high efficiency [1]. For screw compressors, the screw rotor is the main factor that determines the performance of the compressor. Therefore, the optimization design of the rotor has always been the focus of research on screw compressors.

Since the advent of screw compressors, researchers have been working on the optimization of rotors. With the development of computer technology, more complicated equations can be solved. Therefore, from the 1990s, the optimization of the design of the rotor has made rapid progress.

Zhang and Hamilton [2] presented the calculation of the main geometric characteristic of the twin-screw compressor, such as the effect of the sealing line length and blowhole area on compression volume. Stosic et al. [3-5] presented a method of general geometrical definitions for screw machine rotors and their manufacturing tools, and they proposed their own optimized profile. The results showed that a larger element volume and shorter contact line length could improve performance. J S Fleming and Y Tang [6], based on the mathematical model of the complete compressor thermofluid process, studied the internal gas leakages and discussed the manner in which the leakage distribution prediction could be used to optimize a compressor design. Shyh-Haur Su [7] proposed a systematic synthesis method for twin-screw rotor profiles for compressors. Wu and Xing [8] proposed a new mathematical model for calculating the specifications of twin-screw refrigeration compressors. The model took into account multiple leak paths, the heat transfer effects 
of the oil and variable load conditions. Van Erdeweghe, S, et al. [9] presented a modeling of a twin-screw compressor, which can be applied in an optimization procedure to find the optimal rotor profiles for a given application. Stosic [10] summarized the compressor simulation model.

The main indicators that affect the rotor performance are closely related to the contact line. In traditional design, the rotor profile is first generated, and then the contact line can be obtained. However, Zaytsev [11] proposed that a designer could design the mesh line equation without determining the rotor profile in advance, and then the rotor profile could be obtained through the meshing principle and coordinate transformation. According to this idea, $\mathrm{Wu}$ [12] used the cubic spline curve to design the contact line and considered the non-undercut conditions to obtain the corresponding rotor profile. Wu [13] also published a rotor profile design method by using a rack defined in the normal plane. $\mathrm{Xu}$ [14] derived the equation of the profile generated by basic curve placed in the meshing line.

Generally speaking, designers need screw rotors to have the following characteristics: a shorter contact line length to reduce leakage, and a larger discharge port area to optimize the discharge process. The reduction of the lead near the discharge port can achieve the above requirements. Therefore, the variable-lead rotor was proposed.

Recently, scholars have begun to study variable-lead rotors. Rane S, Kovacevic A and Stosic N [15] used CFD calculation software to simulate uniform rotors, variable pitch rotors and variable profile rotors. The results showed that variable pitch rotors have better performance at high pressure ratios. Utri M and Brümmer A [16-18] compared the efficiency of dry screw compressors with uniform and dual lead rotors and optimized the geometric parameters using the Nelder-Mead algorithm. Huang and Chih-Yung [19] studied the efficiency of a variable-lead rotor under the change of speed or interlobe clearance and pointed out that the Bezier curve-type lead was better.

This paper compares the influence of different lead change methods on the contact line and the discharge port. Further, the mathematical model of the compressor is used to simulate and compare the efficiency.

\section{Methods}

This section first briefly introduces the twin screw compressor terminology, as shown in Figure 1. Pitch circles are a pair of imaginary tangential circles centered on the rotor center of female and male rotors. When the female and male rotors rotate, the two circles roll relative to each other without sliding. The wrap angle refers to the angle of rotation of a tooth on the rotor from the suction-end face to the discharge-end face. In this paper, the wrap angle refers to the wrap angle of the male rotor. Figure 2 shows the general shape of the variable-lead rotor discussed in this paper. 


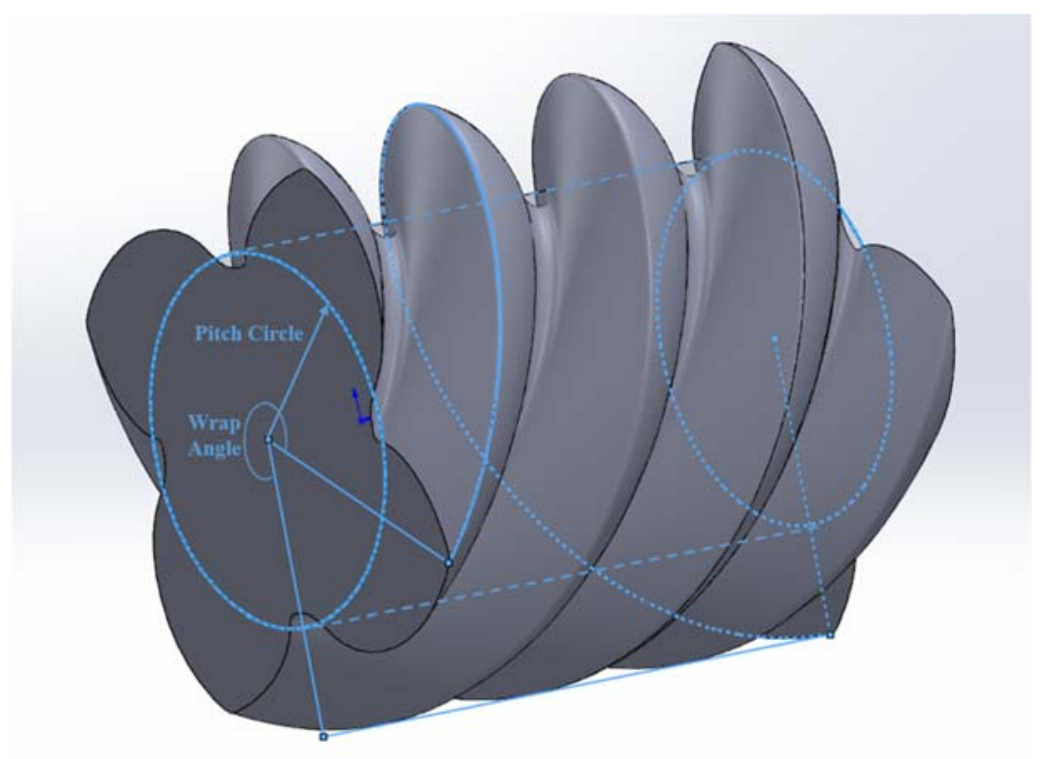

Figure 1. Schematic diagram of screw rotor.

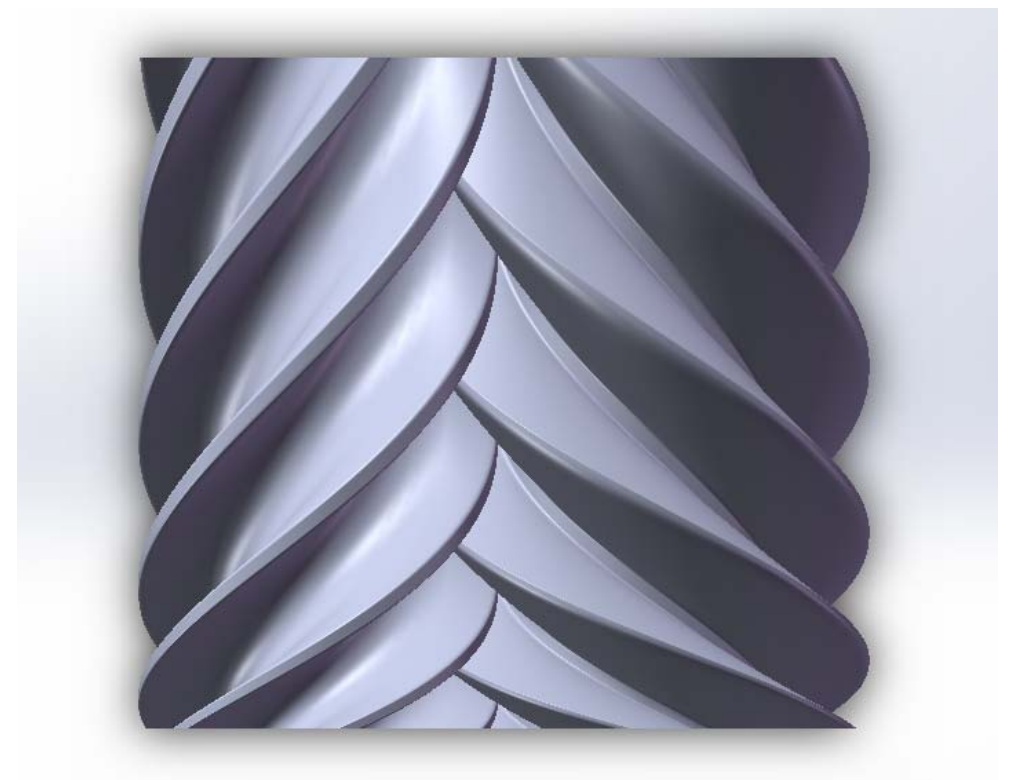

Figure 2. Schematic diagram of variable-lead rotor.

\subsection{Lead Variation}

Generally, the lead of the twin-screw rotor is constant, resulting in a linear relationship between the wrap angle and the pitch. In order to achieve a variable lead, the relationship between the wrap angle and pitch can be redefined. Figure 3 shows the functions between the lead and wrap angle. In this figure, the wrap angle is set to 300 degrees. Taking the constant lead as a reference, different forms of variable lead are shown. For comparison, it is necessary to obtain the same rotor length under the same wrap angle. In other words, the area enclosed by each curve in the graph and the $X$ axis is equal, which is the premise in the subsequent comparison. Further, when the lead variation form and the initial lead are given, the relationship between the lead and the wrap angle could be obtained. Therefore, this study defines the initial lead $L_{\mathrm{i}}$ as the ratio of the lead when the wrap angle is 0 to the constant lead. For example, in Figure $3, L_{\mathrm{i}}=1.2$, where $L_{\mathrm{i}}$ reflects the severity of the lead reduction. A larger $L_{\mathrm{i}}$ means a more severe lead reduction and a smaller lead at the 
discharge side. Figure 4 shows that the change in the chamber volume depends on the rotor rotation angle for different rotor lead changing laws. As can be seen in the figure, the volume of the variable-lead rotor changes at a faster rate, but its maximum theoretical volume is less than that of the constant-lead rotor.

$$
L_{i}=\frac{\text { Lead }_{\text {wrapangle }=0}}{\text { Lead }_{\text {constant }}}
$$

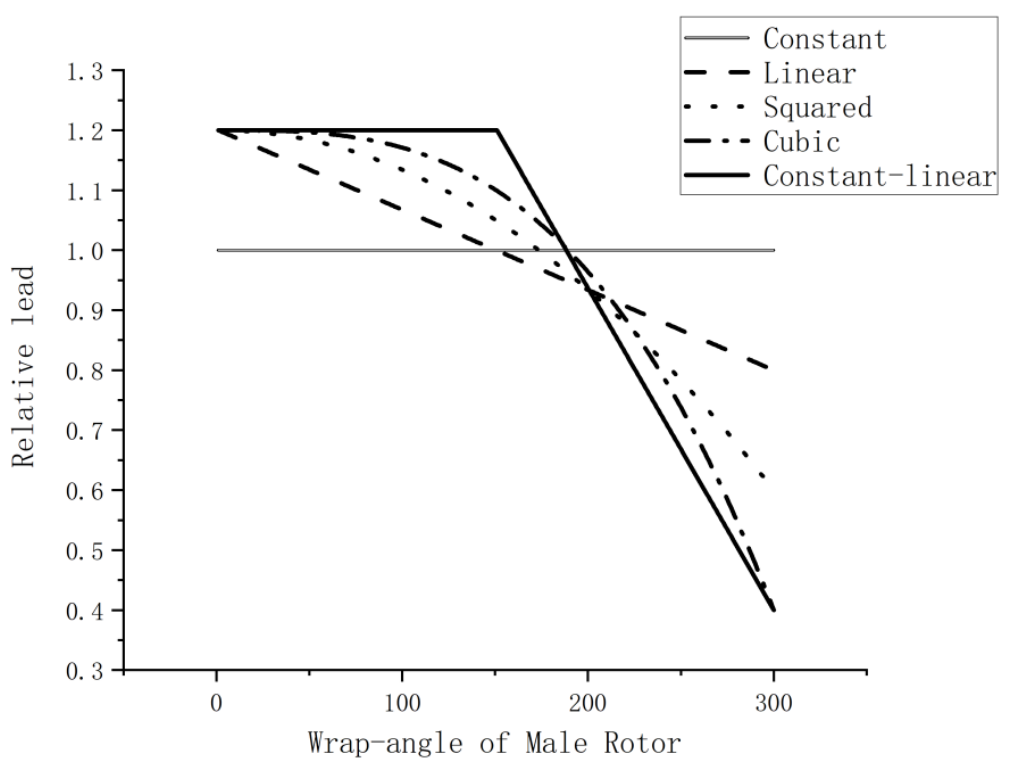

Figure 3. Different functions for lead and wrap angle.

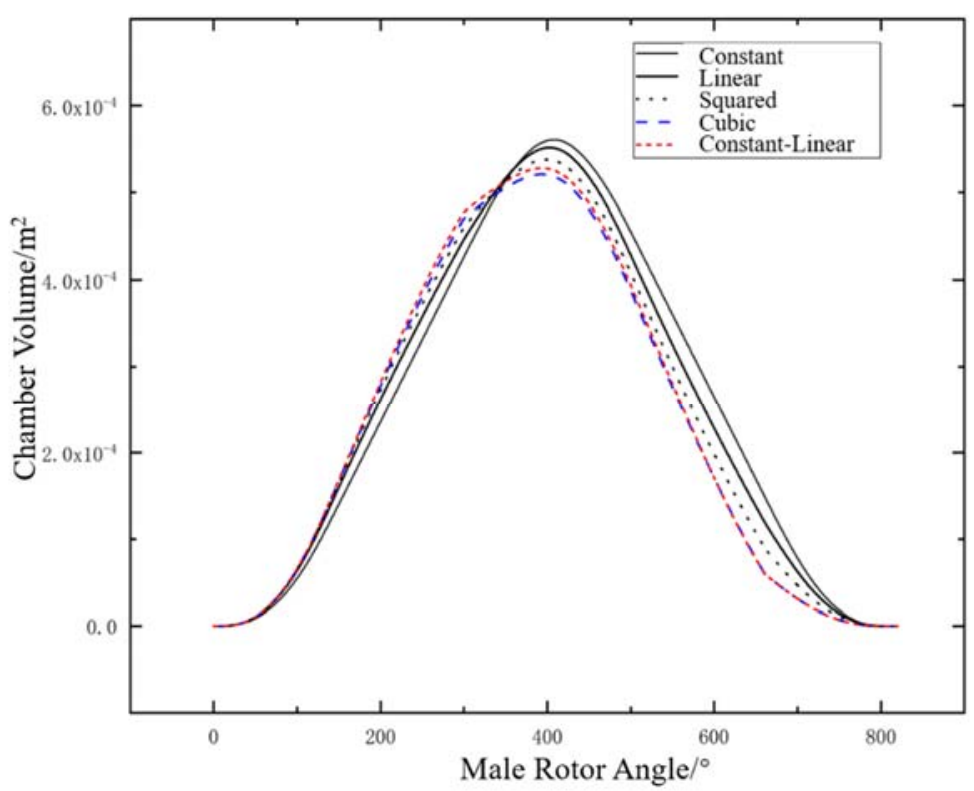

Figure 4. Change of chamber volume depends on rotor rotation angle for different rotor lead changing laws.

\subsection{Changes of Geometric Characteristics}

The change of the lead definitely causes the change of the contact line length, which affects the leakage greatly. Figure 5 shows the change of the contact line length with different lead variation. As shown in this figure, compared to the constant lead, the contact line of the variable-lead rotor is longer at the beginning of compression and gradually 
become shorter. Rotors with decreasing lead have the above characteristics, as studied by Chih-Yung [19].

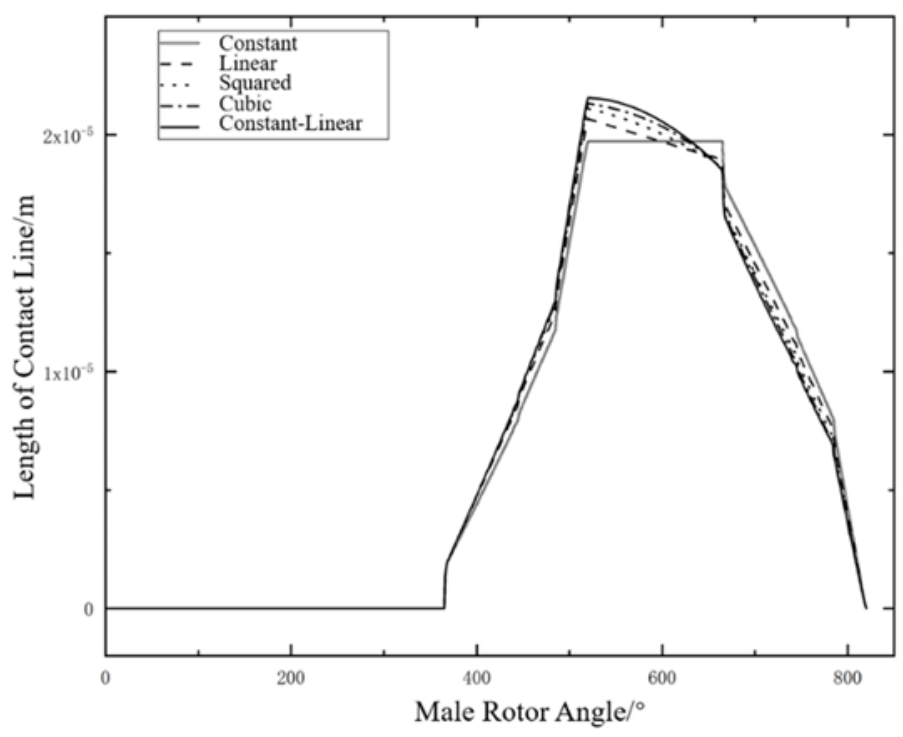

Figure 5. The contact line length with different lead variation.

Reducing the contact line near the discharge transverse plane will reduce the leakage at high pressure, but the increase in the length of the contact line near the suction transverse plane will also increase the leakage at the beginning of compression. Moreover, the volume change of the variable-lead rotor is faster than the constant lead, meaning that high pressure is reached earlier. Therefore, whether the contact line characteristic of the variable-lead rotor ultimately benefits the volumetric efficiency depends on the operating conditions such as the pressure ratio and the rotor speed.

Similarly, since the variable-lead rotor has a faster compression stage and the gas could be compressed to the required pressure in a shorter rotation angle, the area of its discharge port could also be larger. Figure 6 shows the discharge area with different lead variation. It can be seen that reducing the lead near the discharge transverse plane results in a larger discharge area.

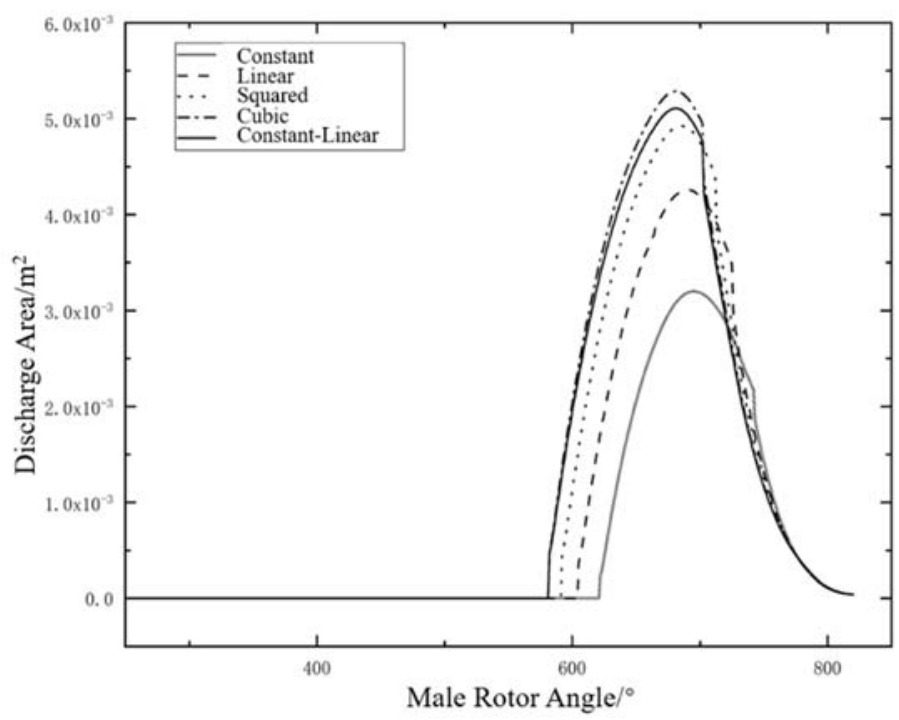

Figure 6. The discharge area with different lead variation. 
On the one hand, the variable-lead rotor will reach the target internal volume ratio earlier due to its larger lead at the beginning of compression, so the discharge angle will be larger than that of the constant rotor. According to the design principle of the discharge port, an smaller discharge angle also means a larger discharge port. As shown in this figure, compared with the constant-lead rotor, the maximum discharge area of the cubic variable lead reaches $160.17 \%$. On the other hand, the variable-lead rotor has a smaller lead at the time of discharge, which will make the volume change rate slow. A larger discharge outlet area and slower volume change rate working together will effectively reduce the gas flow rate during discharge, thereby reducing over-compression loss, throttling and noise.

It is worth mentioning that since a larger $L_{i}$ means a smaller lead near the discharge transverse plane, the increase of $L_{\mathrm{i}}$ will enhance the change trend of the contact line and the discharge port.

\subsection{Compressor Modeling}

In this research, the mathematical model of compressor internal volume established by $\mathrm{Wu}[8]$ is used to simulate the working process. A brief description and the main formulas are shown below.

As shown in Figure 7, the working process of the compressor is simplified as an opening system. Suction, discharge and leak processes are considered as mass changes, and heat transfer is considered as energy change.

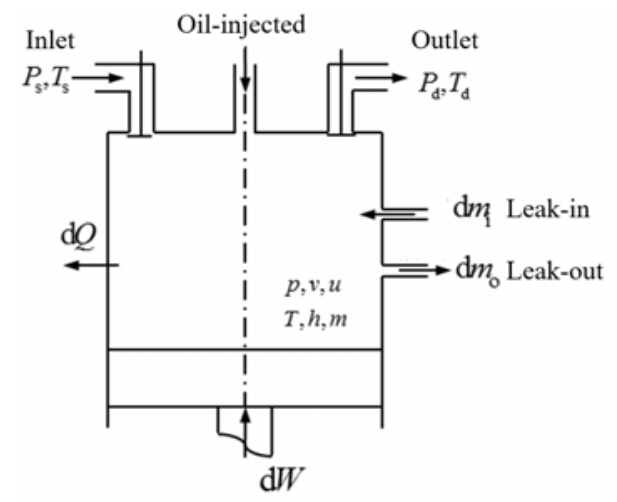

Figure 7. Control volume establishment [8].

In order to use mathematical models to describe complex actual working processes, appropriate simplification is required, so the following basic assumptions are made:

1. There is no heat exchange between the working gas and the environment in the flow process through the inlet and outlet orifice and the leak channel, and it is regarded as an adiabatic compressible fluid. Thus, the nozzle model is used to describe the parameters in the flow process;

2. Within the working volume corresponding to each rotor, the state of all positions is uniform, and there is no difference in local state. Therefore, the state parameters of all points in the whole working volume can be characterized by the same value;

3. The size of the suction cavity and discharge cavity connected to the compressor is regarded as infinite, meaning that the pressure fluctuation in the cavity caused by the suction and discharge process can be ignored;

4. The suction of the screw compressor does not leak, and leakage is only considered in the compression and discharge stage.

The differential form of the energy conservation equation of the compressor working process can be written into the form of formula (2).

$$
\mathrm{d}(m u)=\mathrm{d} E_{\mathrm{i}}-\mathrm{d} E_{\mathrm{o}}-\mathrm{d} Q+\mathrm{d} W
$$


where $m$ is the mass of working gas in the control volume, $u$ is the internal energy of working gas in the control volume, $E_{i}$ is the total internal energy of the leakage into the control volume, $E_{o}$ is the total internal energy of the leakage out of the control volume. $Q$ is the heat transfer between the working gas and the environment, and $W$ is the amount of work input to the control volume.

$\mathrm{d}(m u)$ in formula (2) can be described as shown in formula (3).

$$
\mathrm{d}(m u)=\sum \mathrm{d} m_{\mathrm{i}}\left(h_{\mathrm{i}}+\frac{v_{\mathrm{i}}^{2}}{2}+z_{\mathrm{i}} g\right)-\sum \mathrm{d} m_{\mathrm{o}}\left(h_{\mathrm{o}}+\frac{v_{\mathrm{o}}^{2}}{2}+z_{\mathrm{o}} g\right)-\mathrm{d} Q+\mathrm{d} W
$$

where $\mathrm{d} m_{i}$ is the mass of the leakage into the control volume, $h_{i}$ is the specific enthalpy of the leakage into the control volume, $v_{i}$ is the velocity of the leakage into the control volume, $z_{i}$ is the height between the input leakage position and reference position, $g$ is the acceleration of gravity, $\mathrm{d} m_{o}$ is the mass of the leakage out of the control volume, $h_{o}$ is the specific enthalpy of the leakage out of the control volume, $v_{0}$ is the velocity of the leakage out of the control volume, and $z_{0}$ is the height between the output leakage position and reference position.

According to formula (3), based on Hypothesis (2), ignoring the kinetic and gravitational potential energy and taking the derivative with respect to time, the rotation speed of the rotor is considered as a constant, and thus we obtain formula (4).

$$
\frac{\mathrm{d}(m u)}{\mathrm{d} \varphi}=\sum \frac{\mathrm{d} m_{\mathrm{i}}}{\mathrm{d} \varphi} h_{\mathrm{i}}-\sum \frac{\mathrm{d} m_{\mathrm{o}}}{\mathrm{d} \varphi} h_{\mathrm{o}}+\frac{\mathrm{d} W}{\mathrm{~d} \varphi}-\frac{\mathrm{d} Q}{\mathrm{~d} \varphi}
$$

where $\varphi$ is the degree of rotation.

According to the relationship between enthalpy and internal energy, as well as the basic gas thermodynamic state equation, the rate equations of pressure and temperature change with rotation angle are derived and shown in formulas (5) and (6).

$$
\begin{gathered}
\frac{\mathrm{d} p}{\mathrm{~d} \varphi}=\frac{\frac{1}{v}\left[\left(\frac{\partial h}{\partial v}\right)_{T}-\frac{(\partial h / \partial T)_{v}(\partial p / \partial v)_{T}}{(\partial p / \partial T)_{v}}\right]-\frac{1}{V_{\mathrm{c}}}\left[\sum \frac{\mathrm{d} m_{\mathrm{i}}}{\mathrm{d} \varphi}\left(h_{\mathrm{i}}-h\right)-\frac{\mathrm{d} Q}{\mathrm{~d} \varphi}\right]}{1-\frac{1}{v} \frac{\partial \partial / \partial T)_{v}}{(\partial p / \partial T)_{v}}} \\
\frac{\mathrm{d} T}{\mathrm{~d} \varphi}=\frac{\left[\frac{1}{v}\left(\frac{\partial h}{\partial v}\right)_{T}-\left(\frac{\partial p}{\partial v}\right)_{T}\right] \frac{\mathrm{d} v}{\mathrm{~d} \varphi}-\frac{1}{V_{\mathrm{c}}}\left[\sum \frac{\mathrm{d} m_{\mathrm{i}}}{\mathrm{d} \varphi}\left(h_{\mathrm{i}}-h\right)-\frac{\mathrm{d} Q}{\mathrm{~d} \varphi}\right]}{\left(\frac{\partial p}{\partial T}\right)_{v}-\frac{1}{v}\left(\frac{\partial h}{\partial T}\right)_{v}}
\end{gathered}
$$

where $v$ is the specific volume and $V_{c}$ is the working gas volume in the control volume.

Formulas (5) and (6) can be regarded as the basic equations in numerical simulation. However, the parameters of leakage and heat transfer cannot be obtained directly, so supplementary equations need to be added. There are three supplementary equations: the ideal gas state equation, mass change equation considering leakage and heat transfer equation considering heat transfer.

As the research object of this paper is a dry air compressor, the ideal gas state equation can be used for the gas state equation. The equation of state for an ideal gas is shown below.

$$
p v=R T
$$

In this paper, the nozzle formula of isentropic flow is used to calculate the mass change caused by leakage. The nozzle formula is shown as follows.

$$
\left\{\begin{array}{cl}
\frac{\mathrm{d} m}{\mathrm{~d} \varphi}=\frac{C A p_{1}}{\omega} \sqrt{\frac{\kappa}{R(\kappa-1)}\left(\frac{2}{(\kappa+1)}\right)^{\frac{\kappa+1}{\kappa-1}}} & \text { if } 0 \leq \frac{p_{2}}{p_{1}}<\left(\frac{2}{\kappa+1}\right)^{\frac{\kappa}{\kappa-1}} \\
\frac{\mathrm{d} m}{\mathrm{~d} \varphi}=\frac{C A p_{1}}{\omega} \sqrt{\frac{2 \kappa}{(\kappa-1) R T_{1}}\left(\left(\frac{p_{2}}{p_{1}}\right)^{\frac{2}{\kappa}}-\left(\frac{p_{2}}{p_{1}}\right)^{\frac{\kappa+1}{\kappa}}\right)} & \text { if }\left(\frac{2}{\kappa+1}\right)^{\frac{\kappa}{\kappa-1}} \leq \frac{p_{2}}{p_{1}} \leq 1
\end{array}\right.
$$


where $p_{1}$ and $p_{2}$ are pressures in the high and low-pressure areas, respectively; $T_{1}$ is the temperature in the high-temperature areas; $A$ is the leakage area of the leakage channel; $C$ is the flow coefficient of the leakage model; $\omega$ is the rotation speed of the rotor; and $\kappa$ is the entropy index.

For the heat transfer equation, this paper only considers the heat transfer with the housing; the heat transfer equation is as follows:

$$
\frac{\mathrm{d} Q_{\mathrm{w}}}{\mathrm{d} \varphi}=\omega(\alpha A)\left(T-T_{\mathrm{w}}\right)
$$

where $\alpha$ is the surface heat transfer coefficient, $A$ is the heat transfer area, and $T_{\mathrm{w}}$ is the housing temperature.

Combining the above supplementary equations with the basic equations, the law of pressure and temperature change with angle in the working volume of the screw compressor can be obtained. In order to improve the accuracy of the solution, the fourth order Runge-Kutta method is used for iterative calculations, and the specific calculation formula is as follows:

$$
\left\{\begin{array}{l}
K_{1}=h f\left(x_{\mathrm{i}}, y_{\mathrm{i}}\right) \\
K_{2}=h f\left(x_{\mathrm{i}}+\frac{1}{4} h, y_{\mathrm{i}}+\frac{1}{4} K_{1}\right) \\
K_{3}=h f\left(x_{\mathrm{i}}+\frac{3}{8} h, y_{\mathrm{i}}+\frac{3}{32} K_{1}+\frac{9}{32} K_{2}\right) \\
K_{4}=h f\left(x_{\mathrm{i}}+\frac{12}{13} h, y_{\mathrm{i}}+\frac{1932}{2197} K_{1}-\frac{7200}{2197} K_{2}+\frac{7296}{2197} K_{3}\right) \\
K_{5}=h f\left(x_{\mathrm{i}}+h, y_{\mathrm{i}}+\frac{439}{216} K_{1}-8 K_{2}+\frac{3680}{513} K_{3}-\frac{845}{4104} K_{4}\right) \\
K_{6}=h f\left(x_{\mathrm{i}}+\frac{1}{2} h, y_{\mathrm{i}}-\frac{8}{27} K_{1}+2 K_{2}-\frac{3544}{2565} K_{3}+\frac{1859}{4104} K_{4}-\frac{11}{40} K_{5}\right) \\
y_{\mathrm{i}+1}=y_{\mathrm{i}}+\left(\frac{16}{135} K_{1}+\frac{6656}{12825} K_{3}+\frac{28561}{56430} K_{4}-\frac{9}{50} K_{5}+\frac{2}{55} K_{6}\right)
\end{array}\right.
$$

Simply put, the iterative step is used to calculate the pressure $p_{i+1}$, temperature $T_{i+1}$ and other parameters corresponding to the next rotation angle $\theta_{i+1}$ through the RungeKutta method through the parameters such as the previous step's rotation angle $\theta_{i}$, pressure $p_{i}$ and temperature $T_{i}$ under the condition of preset step length $h$.

\subsection{Experimental Verification}

In Section 2.3, a mathematical model of the working process of the compressor is established. In order to verify the correctness of the model, a dry screw air compressor unit test run is carried out in this section. Figure 8 shows the performance test platform of the twin screw air compressor used for this model verification, and Figure 9 shows the system flow chart of the experimental platform.

As shown in Figure 9, the temperature and pressure sensor located in front of the compressor inlet air filter is used to measure the inlet air state in this experiment, and the temperature and pressure sensor located in the compressor outlet flow channel is used to measure the discharge air state. The final volume flow rate is measured by a flowmeter located behind the globe valve.

Table 1 shows the main measuring instrument parameters used in this experiment. All instruments in this test are connected to the data acquisition system through the control cabinet to control the operating condition, and then the system for the control of each valve opening adjusts the discharge pressure and other parameters, completing the starting and stopping of the air compressor system. When the compressor starts to run, the data acquisition system continues to analyze and calculate the input electrical signals, real-time flow, temperature, pressure and input power and other numerical feedback to the computer system, displayed in the form of curves. When the monitored data tend to be stable, the 
data are measured every $20 \mathrm{~min}$, the data are collected three times in total, and the results are recorded and printed.

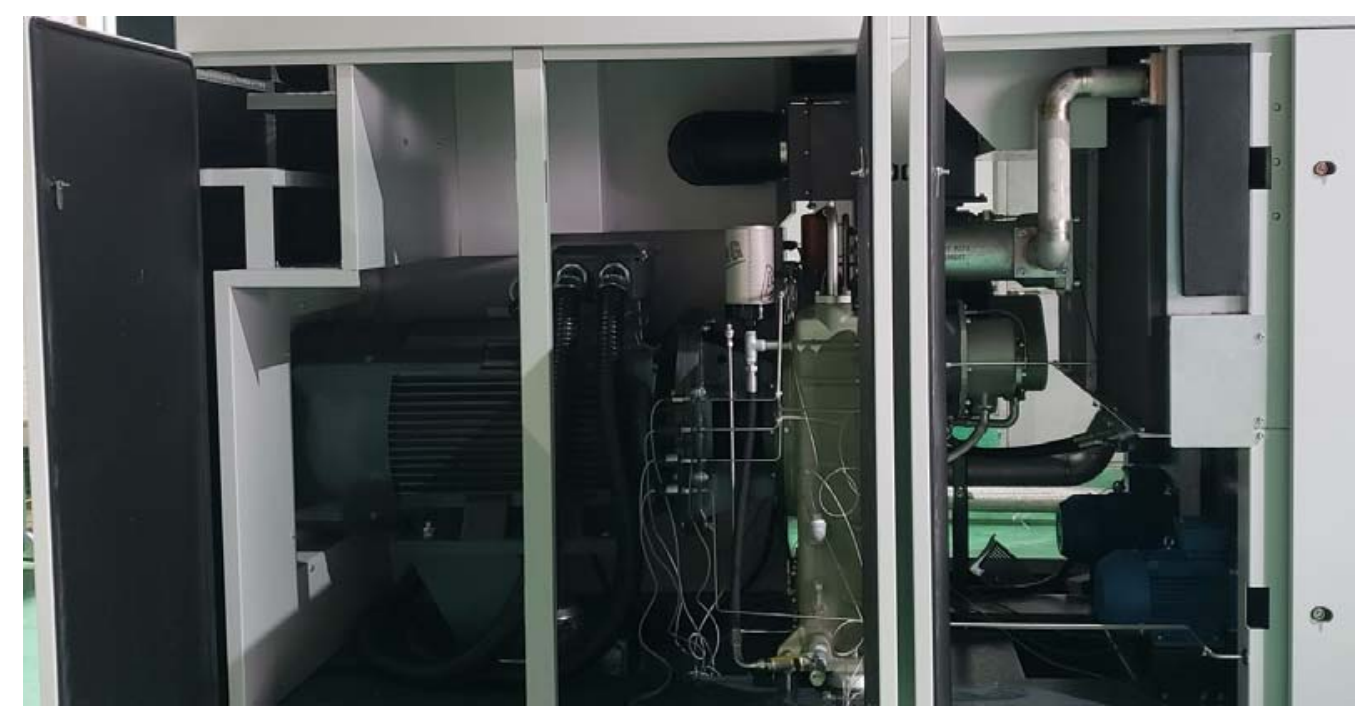

Figure 8. The performance test platform of the twin-screw air compressor.

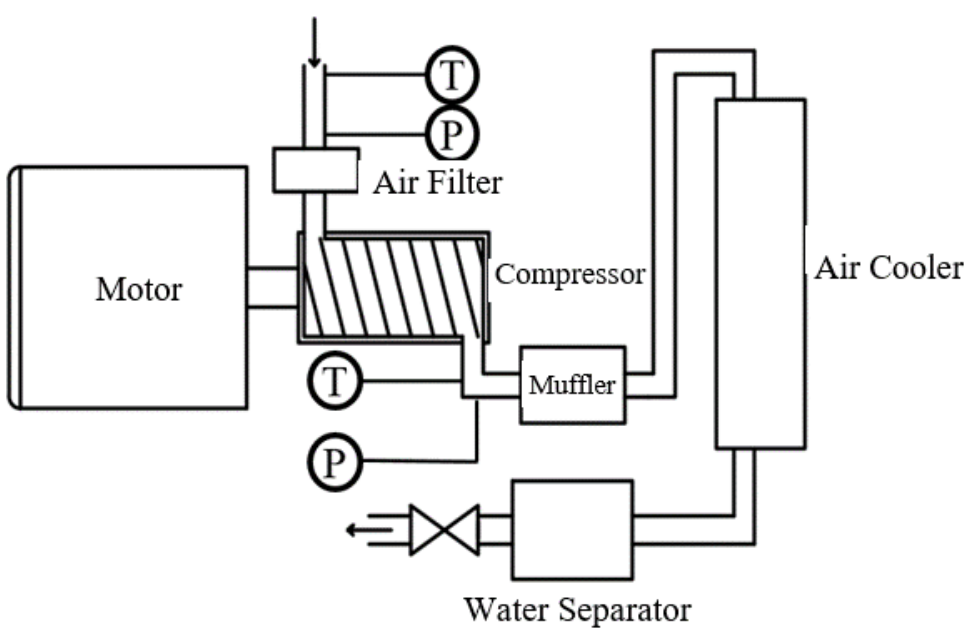

Figure 9. Flow chart of single-stage oil-free air compressor test system.

Table 1. The main measuring instrument parameters.

\begin{tabular}{cccc}
\hline Measuring Content & Sensor & Measuring Range & Precision Grade \\
\hline Temperature $/{ }^{\circ} \mathrm{C}$ & Platinum resistance $(\mathrm{pt100)}$ & $-200 \sim 500$ & \pm 0.1 \\
Pressure $/ \mathrm{MPa}$ & Pressure transmitter & $0 \sim 1.6$ & $\pm 0.25 \%$ \\
Gas volume & Vortex flowmeter & $10.5 \sim 105$ & $\pm 0.75 \%$ \\
flow $/ \mathrm{m}^{3} \cdot \mathrm{s}^{-1}$ & Digital power meter & $0 \sim 200$ & $\pm 0.1 \%$ \\
Input power $/ \mathrm{kW}$ & & &
\end{tabular}

The rated pressure ratio of the oil-free air compressor selected in this test is 3.82, the rated suction pressure is atmospheric pressure, and the rated rotor speed is $9800 \mathrm{RPM}$. The experiment was carried out under the conditions of $0.25 \mathrm{Mpa}$ and $0.3 \mathrm{Mpa}$ discharge pressure, and the results of experiments and calculations are shown in Tables 2 and 3. 
Table 2. Experimental and simulated data of $0.25 \mathrm{Mpa}$ discharge pressure.

\begin{tabular}{ccccccc}
\hline Category & Test 1 & Test 2 & Test 3 & Average & $\begin{array}{c}\text { Simulation } \\
\text { Value }\end{array}$ & $\begin{array}{c}\text { Relative } \\
\text { Error }\end{array}$ \\
\hline Shaft power $(\mathrm{kW})$ & 95.03 & 94.99 & 94.97 & 95.00 & 93.13 & $-1.96 \%$ \\
Gas volume flow $\left(\mathrm{m}^{3} \cdot \mathrm{h}^{-1}\right)$ & 23.81 & 23.81 & 23.79 & 23.80 & 24.82 & $4.29 \%$ \\
Discharge temperature $\left({ }^{\circ} \mathrm{C}\right)$ & 170.9 & 170.9 & 171.0 & 170.9 & 173.9 & $1.77 \%$ \\
Adiabatic efficiency & 0.4573 & 0.4575 & 0.4572 & 0.4573 & 0.4643 & $1.52 \%$ \\
\hline
\end{tabular}

Table 3. Experimental and simulated data of $0.3 \mathrm{Mpa}$ discharge pressure.

\begin{tabular}{ccccccc}
\hline Category & Test 1 & Test 2 & Test 3 & Average & $\begin{array}{c}\text { Simulation } \\
\text { Value }\end{array}$ & $\begin{array}{c}\text { Relative } \\
\text { Error }\end{array}$ \\
\hline Shaft power $(\mathrm{kW})$ & 102.88 & 102.97 & 102.95 & 102.93 & 103.04 & $0.10 \%$ \\
Gas volume flow $\left(\mathrm{m}^{3} \cdot \mathrm{h}^{-1}\right)$ & 23.58 & 23.61 & 23.61 & 23.60 & 24.15 & $2.32 \%$ \\
Discharge temperature $\left({ }^{\circ} \mathrm{C}\right)$ & 187.2 & 187.4 & 187.3 & 187.3 & 190.2 & $1.59 \%$ \\
Adiabatic efficiency & 0.4925 & 0.4927 & 0.4928 & 0.4926 & 0.5040 & $2.29 \%$ \\
\hline
\end{tabular}

As shown in Tables 2 and 3, compared with the experimental data, the errors of the simulated values are within $\pm 5 \%$, so the simulated results can be used to reflect the actual working process.

\section{Results and Discussion}

This section discusses the influence of different factors on the volumetric efficiency and adiabatic efficiency of compressors. The volumetric efficiency $\eta_{V}$ is $\eta_{V}=q_{V} / q_{V t}$, where $q_{V}$ is the actual volume flow of the compressor converted from the actual discharge flow to the suction state, and $q_{V t}$ is the sum of the volume between the teeth rotated by the rotor in unit time. The volumetric efficiency reflects the leakage of the compressor. The adiabatic efficiency $\eta_{a d}$ is $\eta_{a d}=P_{a d} / P$, where $P_{a d}$ is the power required for isentropic compression, and $P$ is the actual shaft power of the compressor. The adiabatic efficiency reflects the perfection of energy utilization of the compressor.

\subsection{Effect of Lead Variation and $L_{i}$}

The mathematical model was used to simulate the performance of the screw compressor under different working conditions. Table 4 shows the setting values of some related parameters.

Table 4. Parameter settings.

\begin{tabular}{cc}
\hline Parameters & Values \\
\hline Center distance $(\mathrm{mm})$ & 93 \\
Outer diameter of the male rotor $(\mathrm{mm})$ & 130 \\
Outer diameter of the female rotor $(\mathrm{mm})$ & 120 \\
Rotor length $(\mathrm{mm})$ & 195 \\
Male rotor wrap angle $\left.{ }^{\circ}\right)$ & 300 \\
Rotating speed $(\mathrm{rpm})^{\text {Suction pressure }(\mathrm{kPa})}$ & 9000 \\
Internal compression volume ratio & 100 \\
Pressure ratio & 2.5 \\
\hline
\end{tabular}

The simulation results are as follows. Figure 10 shows the change of volume efficiency with different lead functions. On the whole, under the working conditions shown in Table 4, the volumetric efficiency of all variable-lead rotors is lower than the constant lead, and the larger the value of $L_{\mathrm{i}}$, the more obvious the decrease in volumetric efficiency, which is mainly caused by the increase in leakage. As analyzed in the geometric characteristics of the previous section, the variable-lead rotor not only obtains a smaller contact line near the discharge transverse plane, but also increases the length of the contact line near the suction 
transverse plane, which will lead to the same tendency of leakage. In this simulation, the discharge pressure is relatively low, so the difference between the reduced leakage near the discharge transverse plane and the increased leakage near the suction transverse plane is not obvious. However, the volume pressure between the teeth of the variable-lead rotor increases faster, increasing the amount of leakage. This trend becomes more severe with the increase of $L_{\mathrm{i}}$, so the volumetric efficiency decreases with the increase of $L_{\mathrm{i}}$.

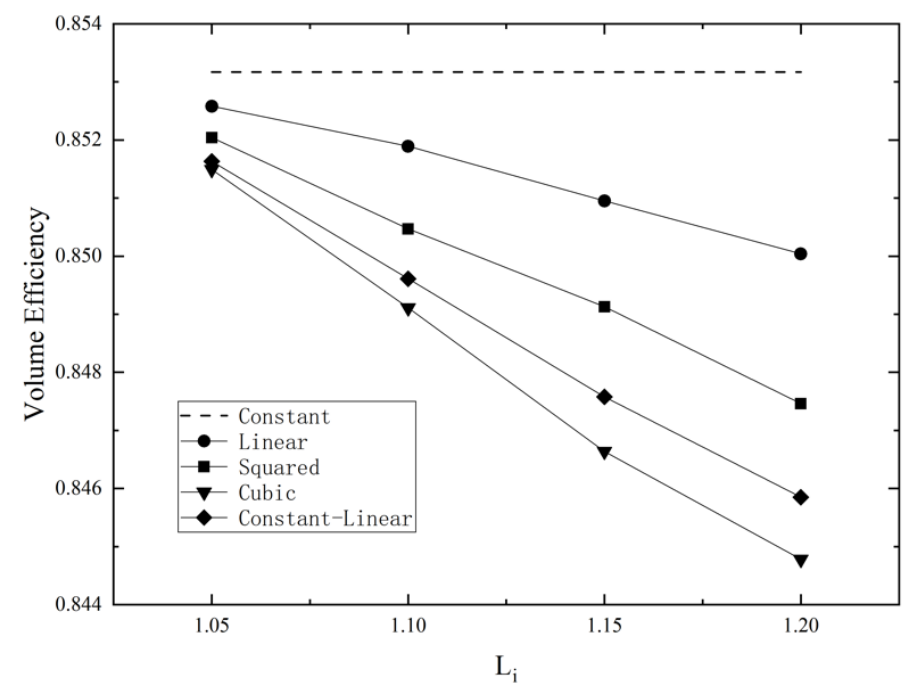

Figure 10. The volume flow of variable-lead rotor varies with $L_{\mathrm{i}}$.

Comparing different variable lead forms, it can be seen that the volumetric efficiency reduction of linear variable lead is the least, while the volumetric efficiency reduction of cubic variable lead is more obvious. The appearance of this situation is also related to the difference in geometric characteristics. Compared with the linear variable lead, the cubic contact line changes more slowly near the suction transverse plane, thereby forming a longer contact line near the suction transverse plane. Furthermore, the gas pressure of the cubic lead rises faster, which leads to increased leakage.

Figure 11 reflects the change of the pressure of the linear variable-lead rotor with $L_{\mathrm{i}}=1.15$ and the constant-lead rotor with the rotation angle of the male rotor. The figure clearly reflects that the pressure of the variable-lead rotor rises faster, and the larger discharge area improves the over-compression situation.

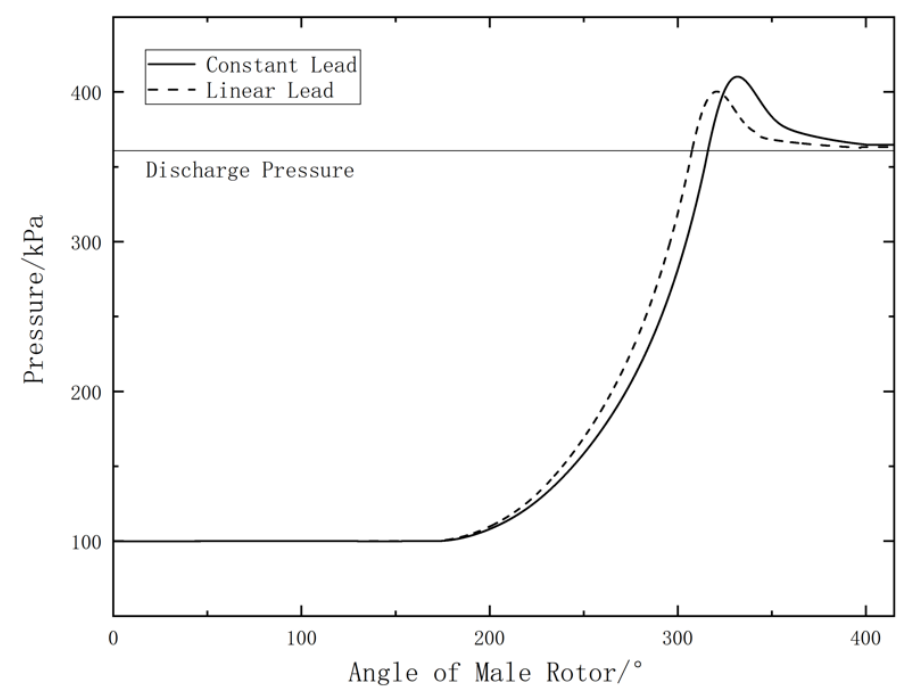

Figure 11. Variable lead and constant rotor pressure-rotation angle. 
As shown in Figure 12, under the simulation conditions, the isentropic efficiency of the variable-lead rotor is generally better than that of the constant-lead rotor. The isentropic efficiency of the linear lead has been on the rise with the increase of $L_{\mathrm{i}}$. As the degree of variable lead increases, the discharge port gradually increases, thereby improving the energy loss of over-compression. The isentropic efficiency of the squared lead, cubic lead and constant-linear lead shows a trend of first rising and then falling with the increase of $L_{\mathrm{i}}$, which is related to the increase of leakage. Considering the change trend of volume efficiency in Figure 10, with the increase of $L_{\mathrm{i}}$, the square, cubic and constant-linear leads are more affected by leakage, so the isentropic efficiency gradually decreases. The isentropic efficiency of the constant-linear lead with $L_{\mathrm{i}}=1.2$ is even reduced to $68.12 \%$, which is lower than the value of $68.33 \%$ for the constant-lead rotor.

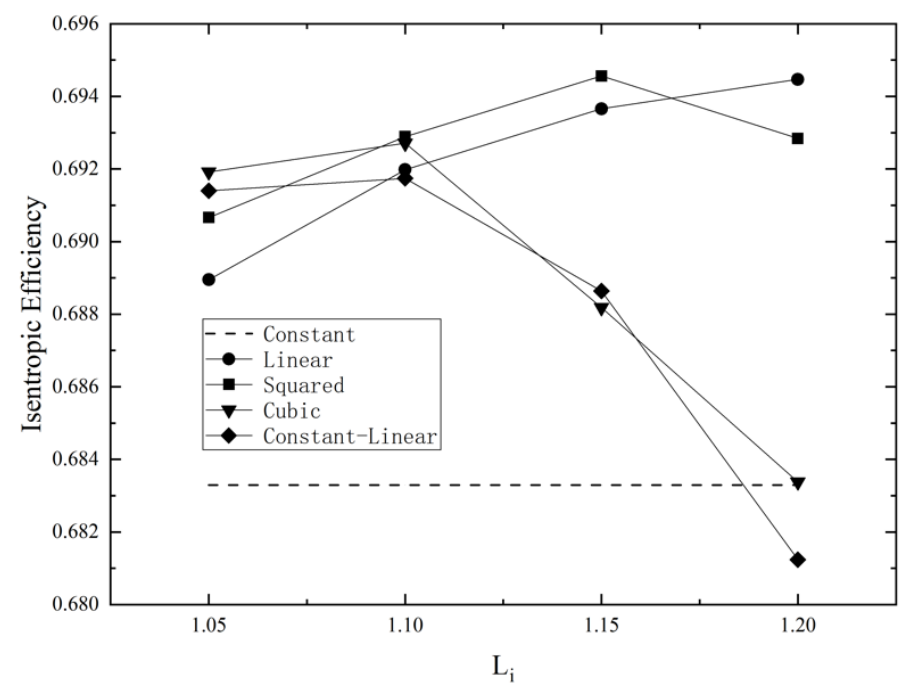

Figure 12. The isentropic efficiency of variable-lead rotor varies with $L_{\mathrm{i}}$.

Both the isentropic efficiency and the volumetric flow rate are important indicators for evaluating the performance of the compressor. Under the simulated operating conditions in this section, the variable-lead rotor improves the isentropic efficiency while reducing the volumetric efficiency. Therefore, it is necessary to comprehensively consider the advantages and disadvantages of the variable-lead rotor.

\subsection{Effect of Wrap Angle and $L_{i}$}

Following the previous experiment, we kept the other parameters in Table 4 fixed, changed the wrap angle and then repeated the simulation.

Figure 13 shows that the volume efficiency of the linear variable-lead rotor with different $L_{\mathrm{i}}$ values varies with the wrap-angle. It can be seen that as the wrap angle increases, the volume efficiency generally decreases gradually, which is the same as Xing's analysis result. In addition, the leakage increases with the increase of the wrap-angle. As for the variable-lead rotor, as analyzed in the previous section, the volume efficiency decreases with the increase of $L_{\mathrm{i}}$. It can be noticed that the volumetric efficiency shows a smaller decrease with the increase of $L_{\mathrm{i}}$ when the wrap angle is small. For example, at a wrap angle of 260 degrees, the volumetric efficiency of the linear variable-lead rotor with $L_{\mathrm{i}}=1.2$ is $85.66 \%$, which is only $0.19 \%$ lower than the constant lead.

Figure 14 shows the trend of isentropic efficiency. Because the speed set by the simulation in this section is $9000 \mathrm{rpm}$, according to the analysis in the previous chapter, at high speeds, as the wrap angle increases, the isentropic efficiency shows an upward trend due to the improvement of discharge loss. All the curves in the figure conform to this rule. The isentropic efficiency of all linear variable leads is also higher than that of constant leads. Based on the analysis of the geometrical characteristics of the previous article, the increase in isentropic efficiency is also due to the increase in the discharge port. It is worth 
noting that when the wrap angle is small, the increase of $L_{\mathrm{i}}$ of the linear variable-lead rotor will bring about a greater improvement in isentropic efficiency. At a wrap angle of 260 degrees, the isentropic efficiency with $L_{\mathrm{i}}=1.2$ reaches $68.06 \%$, which is an increase of $2.75 \%$ compared to the constant lead, while the amplitude is only $0.75 \%$ at 320 degrees. Combined with the analysis of the geometric characteristics in the previous chapter, when the wrap angle is small, the original discharge port area is smaller, and the discharge loss has a greater impact on the isentropic efficiency. Therefore, the increase of the discharge port brought by the variable lead will more obviously increase the efficiency.

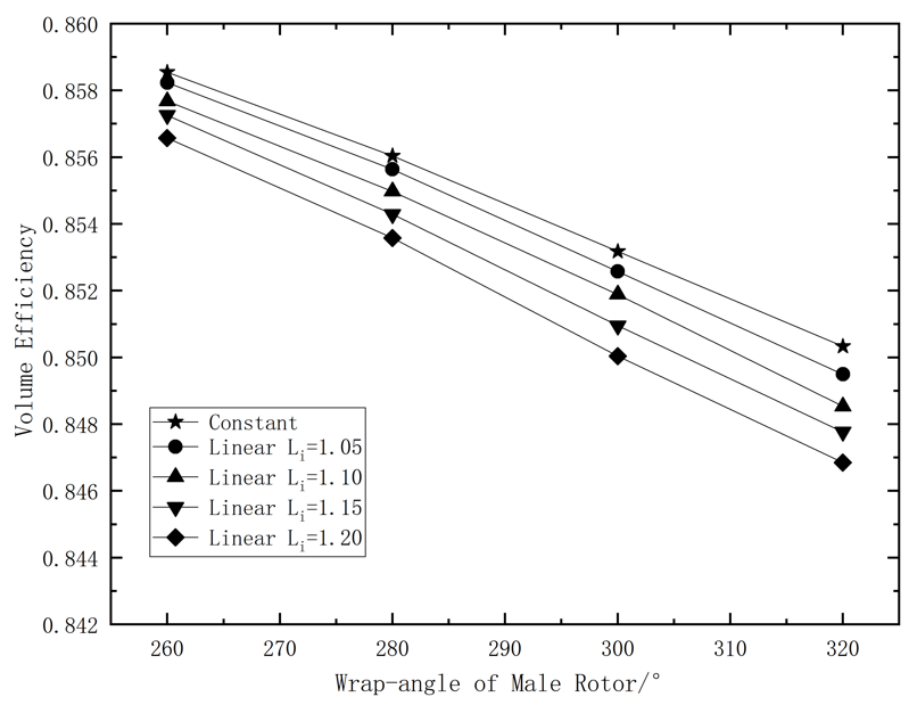

Figure 13. The volume efficiency of linear lead rotor varies with wrap angle.

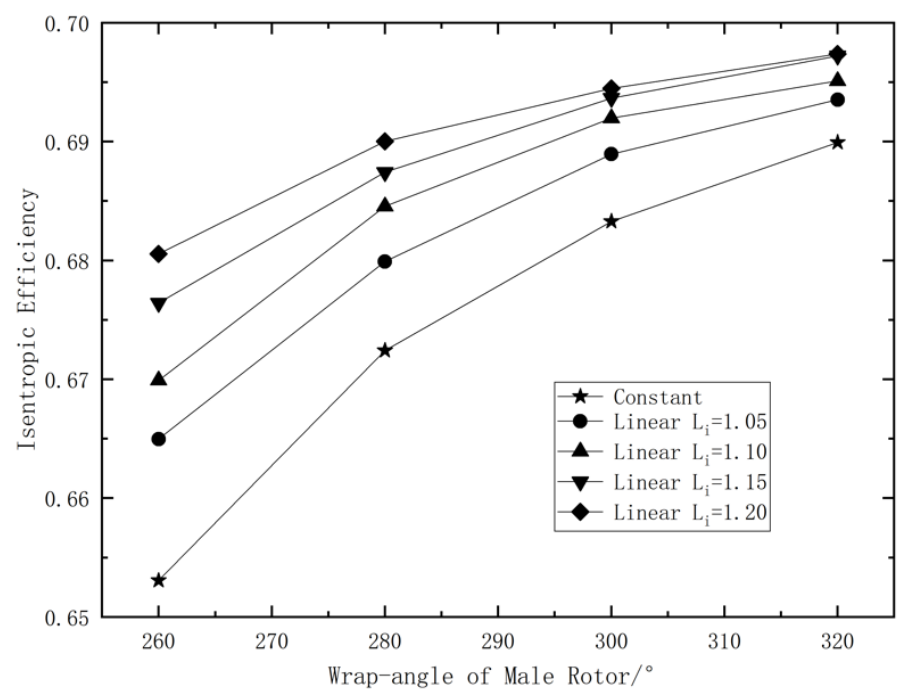

Figure 14. The isentropic efficiency of linear lead rotor varies with wrap angle.

\subsection{Effect of Internal Volume Ratio and $L_{i}$}

The internal volume ratio has a great influence on the selection of rotor parameters, so the working process was simulated after changing the internal volume ratio.

Figure 15 shows the change trend of volume efficiency under different internal volume ratios. First of all, as the inner volume ratio increases, the volume efficiency of the variablelead rotor also shows a downward trend, which is the same as the change of the constant lead. Then, it can be seen that when the internal volume ratio is 2.5 , the volume efficiency of the variable-lead rotor is lower than the constant lead. This phenomenon has been explained in detail above. However, when the internal volume ratio increases, the variable- 
lead rotor has a short contact line near the discharge transverse plane and reduces leakage gradually. When the internal volume ratio is 3 , the volume efficiency of a linear lead rotor with $L_{\mathrm{i}}=1.05$ is higher than that of a constant-lead rotor with the same internal volume ratio. When the internal volume ratio is 3.5 , the volume efficiency reaches the highest value with $L_{\mathrm{i}}=1.1$. According to the trend in the figure, it can be predicted that at a higher internal volume ratio, a variable-lead rotor with a larger $L_{\mathrm{i}}$ value can achieve the purpose of reducing leakage and improving volume efficiency through a shorter contact line near the discharge transverse plane.

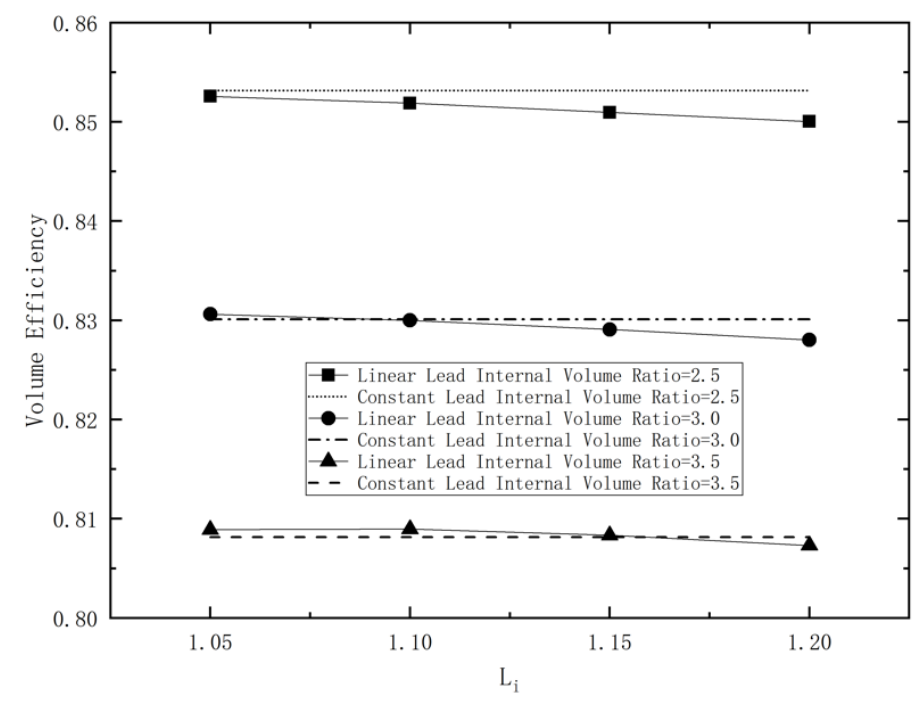

Figure 15. The volume efficiency of linear lead rotor at different internal volume ratios.

Next, we focus on isentropic efficiency. As shown in Figure 16, as the content-tovolume ratio increases, the variable lead improves the isentropic efficiency more obviously. When the internal volume ratio is 3.5, the isentropic efficiency is $4.32 \%$ higher than the constant lead when $L_{\mathrm{i}}=1.2$. On the one hand, the large internal volume ratio will delay the discharge angle, thereby reducing the discharge port area. In this case, the larger discharge port area of the variable-lead rotor will more prominently improve the discharge loss. On the other hand, combined with the trend of volume efficiency in Figure 15, when the volume ratio is large, the influence of the variable lead on leakage gradually changes from an increase to a decrease, thereby improving the isentropic efficiency.

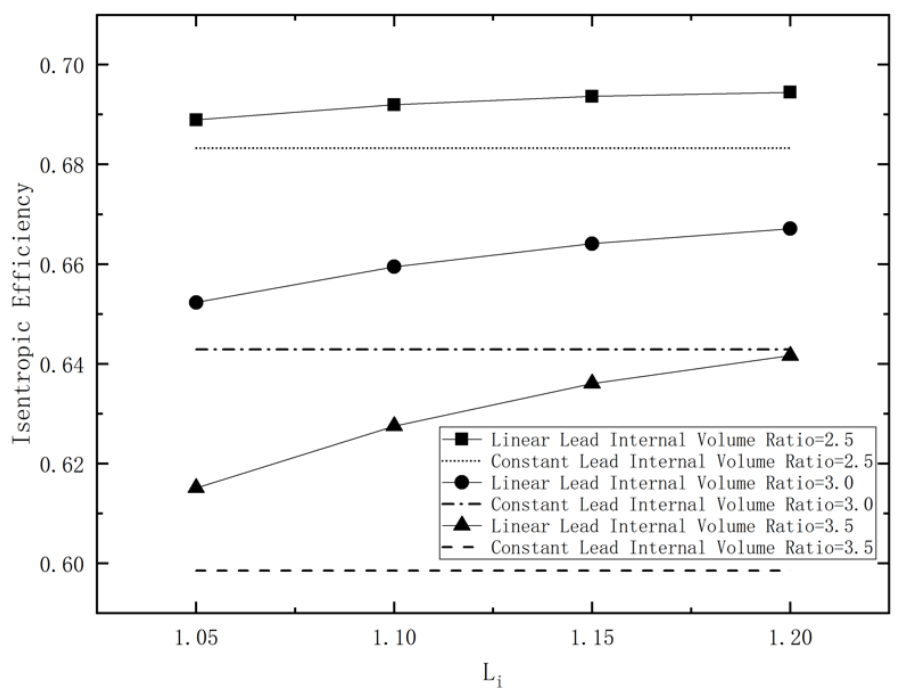

Figure 16. The isentropic efficiency of constant-linear lead rotor at different internal volume ratios. 


\section{Conclusions}

In this research, the parameter $L_{\mathrm{i}}$ was proposed to measure the intensity of variable lead, using mathematical models to simulate the working process and analyzing the performance of different variable lead functions. Further, the effect of the wrap angle and internal volume ratio on performance was studied. After the comparisons of geometric data and simulation results, the following conclusions were obtained:

1. Compared with a constant-lead rotor, a decreasing-lead rotor has a longer contact line near the suction transverse plane and a shorter contact line near the discharge transverse plane, causing a decreasing-lead rotor to exhibit a large leakage near the suction transverse plane but less leakage near the discharge transverse plane;

2. Compared with constant-lead rotors, when the internal compression volume ratiowhich is 2.5 in this paper-is relatively low, variable-lead rotors always have lower volume efficiency but higher isentropic efficiency;

3. Compared with constant-lead rotors, variable-lead rotors have a smaller volume efficiency decrease and larger isentropic efficiency increase when the wrap angle is relatively small. As the internal compression volume ratio increases, the performance of variable-lead rotors improves.

In summary, this article provides some references for the design and optimization of compressor rotors.

Author Contributions: Supervision, H.W.; writing—review and editing, J.L.; investigation, Y.S.; writing - original draft preparation, M.L.; software, B.Z. All authors have read and agreed to the published version of the manuscript.

Funding: This research was funded by [the State Key Laboratory of Compressor Technology Open Fund Project] grant number [SKL-YSJ201805].

Institutional Review Board Statement: Not applicable.

Informed Consent Statement: Not applicable.

Conflicts of Interest: The authors declare no conflict of interest.

\section{References}

1. Wu, Y.-R.; Tran, V.-T. Dynamic response prediction of a twin-screw compressor with gas-induced cyclic loads based on multi-body dynamics. Int. J. Refrig. 2016, 65, 111-128. [CrossRef]

2. Zhang, L.; Hamilton, J.F. Main geometric characteristics of the twin screw compressor. In Proceedings of the 1992 International Compressor Engineering Conference, West Lafayette, IN, USA, 14-17 July 1992; pp. 449-456.

3. Stosic, N.; Hanjalic, K. General Method for Screw Compressor Profile Generation. In Proceedings of the 1996 International Compressor Engineering Conference at Purdue, West Lafayette, IN, USA, 23-26 July 1996; pp. 157-162.

4. Stosic, N.; Hanjalic, K. Development and optimization of screw machines with a simulation model. J. Fluids Eng. 1997, 119, 658-663.

5. Stosic, N.; Smith, I.K.; Kovacevic, A. The Design of a Twin-screw Compressor Based on a New Rotor Profile. J. Eng. Des. 1997, 8, 389-399. [CrossRef]

6. Fleming, J.S.; Tang, Y. The Analysis of Leakage in a Twin Screw Compressor and its Application to Performance Improvement. J. Process Mech. Eng. 1995, 209, 125-136. [CrossRef]

7. Su, S.-H.; Tseng, C.-H. Synthesis and optimization for rotor profiles in twin rotor screw compressors. J. Mech. Des. Trans. ASME 2000, 122, 543-552. [CrossRef]

8. Huagen, W.; Ziwen, X.; Pengcheng, S. Theoretical and experimental study on indicator diagram of twin screw refrigeration compressor. Int. J. Refrig. 2004, 27, 331-338. [CrossRef]

9. Van Erdeweghe, S.; De Schutter, J.; Van Den Bulck, E. Integral modeling of a twin-screw compressor. J. Mech. Des. Trans. ASME 2016, 138, 073401. [CrossRef]

10. Stosic, N.; Smith, I.K.; Kovacevic, A.; Mujic, E. Review of Mathematical Models in Performance Calculation of Screw Compressors. Int. J. Fluid Mach. Syst. 2011, 4, 271-288. [CrossRef]

11. Zaytsev, D.; Infante Ferreira, C.A. Profile generation method for twin screw compressor rotors based on the meshing line. Int. J. Refrig. 2005, 28, 744-755. [CrossRef]

12. Wu, Y.R.; Fong, Z.H. Improved rotor profiling based on the arbitrary sealing line for twin-screw compressors. Mech. Mach. Theory 2008, 43, 695-711. [CrossRef] 
13. Wu, Y.R.; Fong, Z.H. Rotor profile design for the twin-screw compressor based on the normal-rack generation method. J. Mech. Des. Trans. ASME 2008, 130, 042601. [CrossRef]

14. Xu, J.; Zhou, E.M.; Xu, L.S.; Yu, X.L.; Feng, Q.K. Study on Rotor Profile Design of Screw Compressors Based Upon Meshing Line Method. Compress. Technol. 2013, 1,1-7.

15. Rane, S.; Kovacevic, A.; Stosic, N.; Kethidi, M. Deforming grid generation and CFD analysis of variable geometry screw compressors. Comput. Fluids 2014, 99, 124-141. [CrossRef]

16. Utri, M.; Brümmer, A. Opportunities for variable rotor lead in screw compressors depending on dimensionless numbers. J. Process Mech. Eng. 2018. [CrossRef]

17. Utri, M.; Brummer, A. Improvement of the efficiency of twin-screw refrigeration compressors by means of dual lead rotors. In Proceedings of the International Compressor Engineering Conference, West Lafayette, IN, USA, 11-14 July 2016 ; p. 1428.

18. Utri, M.; Brummer, A. Energy potential of dual lead rotors for twin screw compressors. IOP Conf. Ser. Mater. Sci. Eng. 2017, 232, 012018. [CrossRef]

19. Huang, C.Y. New Twin Screw Compressor Design by Deviation Function Method. Ph.D. Thesis, University of California, Los Angeles, IN, USA, 2015. 